\title{
Clinical Evaluation of Chinese Patients with Primary Distal Renal Tubular Acidosis
}

\author{
Chunli Zhang, Hong Ren, Pingyan Shen, Yaowen Xu, Wen Zhang, Weiming Wang, \\ Xiao Li, Yuhuan Ma and Nan Chen
}

\begin{abstract}
Objective Distal renal tubular acidosis (dRTA) is a hyperchloremic metabolic acidosis disorder characterized by a normal anion gap with abnormal urinary hydrogen $\left(\mathrm{H}^{+}\right)$excretion. At present, there are few available reports regarding the clinical status of primary dRTA. The primary objective of this study was to analyze the clinical features and outcomes of primary dRTA.

Methods This was a retrospective study performed in patients with primary dRTA who were hospitalized at Ruijin Hospital between March 1996 and July 2009; the clinical features of these patients were analyzed.

Results This study included 95 consecutive inpatients: 40 men (42.11\%) and 55 women (57.89\%). Among them, 60 had hypokalemia (63.12\%), 29 had complete dRTA and 66 had incomplete dRTA. The mean urine calcium levels of the patients with and without urinary lithiasis were $0.10 \pm 0.04$ and $0.07 \pm 0.05 \mathrm{mmol} / 24 \mathrm{~h} \cdot \mathrm{kg}$, respectively $(\mathrm{p}=0.04)$. The blood $\mathrm{pH}$ values of the patients with and those without bone disease were $7.37 \pm$ 0.06 and $7.32 \pm 0.06$, respectively ( $\mathrm{p}=0.01$ ). A total of $8.33 \%$ (8/27) of the patients had tubular proteinuria.

Conclusion Hypokalemia is the most common clinical manifestation of primary dRTA. Primary dRTA can also be accompanied by proximal tubular dysfunction. Controlling the urine calcium and citrate levels is crucial for the treatment of nephrocalcinosis and/or nephrolithiasis, while restoring the blood $\mathrm{pH}$ to the normal level is essential for controlling bone disease.
\end{abstract}

Key words: primary distal renal tubular acidosis, hypokalemia, kidney stones

(Intern Med 54: 725-730, 2015)

(DOI: 10.2169/internalmedicine.54.9421)

\section{Introduction}

Distal renal tubular acidosis (dRTA) is a hyperchloremic metabolic acidosis disorder characterized by a normal anion gap with abnormal urinary hydrogen $\left(\mathrm{H}^{+}\right)$excretion. The pathogenesis of this disease is due to the dysfunction of $\alpha$ intercalated cells located in collecting tubules that secrete protons into the tubular lumen (1). Patients with dRTA also present with alkaline urine, hypokalemia, nephrolithiasis and chronic acidosis. These conditions significantly impact the quality of life in untreated individuals and can lead to growth failure, osteoporosis, rickets and even renal insufficiency (2-5). Clinically, dRTA can occur as a primary or secondary disease (4). Primary dRTA often appears in inherited and sporadic forms (6); however, few published data are available regarding the clinical manifestations of primary dRTA (7).

The objective of this study was to elucidate the clinical features of primary dRTA by analyzing the clinical data of 95 primary dRTA patients hospitalized at Shanghai Ruijin Hospital between March 1996 and July 2009.

\section{Materials and Methods}

The records of patients with primary dRTA treated at Shanghai Ruijin Hospital between March 1996 and July 2009 were reviewed.

Patients with hypokalemia or recurrent kidney stones were suspected to have dRTA. The diagnosis of dRTA was made primarily based on the clinical phenotype, history, hematological indices and results of urinary acidification 
tests (4, 8-10). Information regarding sex, age at diagnosis, duration from onset to diagnosis, initial symptoms and symptoms correlated with hypokalemia, bone disease and manifestations of kidney injury was also referenced. In addition, data for family history, work history, previous disease records, medication history (i.e., herbs containing aristolochic acid, antibiotics, cotton-seed oil and analgesics), history of urinary tract infections and history of urinary lithiasis were collected.

The laboratory examinations included measurements of the red blood cell count, a urinalysis, liver and renal function parameters, an artery blood gas analysis, the levels of alkaline phosphatase, glucose, parathyroid hormone, blood and urine synchronic electrolytes (i.e., sodium, potassium, chlorine, calcium, phosphonium and carbon dioxide combining power) and urine protein electrophoresis. The urine titratable acid assay was performed to determine the renal acidification function by testing the urine $\mathrm{pH}, \mathrm{HCO}_{3}^{-}$, titratable acidity (TA) and $\mathrm{NH}_{4}^{+}$. Immunoassays for immunoglobulins (i.e., $\operatorname{IgG}, \operatorname{IgA}$ and $\operatorname{IgM}$ ), rheumatoid factor, antinuclear antibodies, anti-single strand DNA, anti-dsDNA, anti-SSA, anti-SSB, anti-ribonucleoprotein, anti-Smith antibodies, cryoglobulin, antimitochondrial antibodies and hepatitis B virus serum markers as well as a cold agglutination test were performed to exclude a diagnosis of secondary dRTA and/or other genetic diseases that could result in secondary dRTA.

Chronic kidney disease (CKD) was diagnosed and staged according to the K/DOQI guidelines. The kidney function of patients older than 16 years of age was evaluated using the Cock-Gault and simplified MDRD formulas, whereas that of patients younger than 16 years of age was evaluated using the Schwartz formula.

The imaging examinations consisted of kidney ultrasound, measurement of left-hand wrist bone age, chest, skull, pelvic, lumbar, vertebral and long bone X-ray and kidney, ureter, bladder and intravenous pyelography. If dilatation of the ureter or hydronephrosis without stones were found on kidney ultrasound, computed tomography was performed. If necessary, magnetic resonance imaging of the lumbar vertebrae and an examination of the bone mineral density (BMD) were performed. Patients with osteoporosis, pathological bone fractures or bone deformities and retardation of bone age in children were diagnosed with bone disease. EKG was also performed.

dRTA was diagnosed based on the following criteria: (1) hyperchloremic metabolic acidosis with a normal anion gap (AG)(blood AG12 $\pm 2 \mathrm{mmol} / \mathrm{L}$,blood Cl->105 mmol/L,blood $\mathrm{pH}<7.35$ or $\mathrm{HCO}_{3} \leq 22 \mathrm{mmol} / \mathrm{L}$ ); (2) the inability to lower the urinary $\mathrm{pH}$ (urine $\mathrm{pH}>6$ ), even with severe metabolic acidosis; (3) a reduction in the levels of urine TA and $\mathrm{NH}_{4}^{+}$ on urine acidification function tests (urine titratable acid assay)(urine TA $<10 \mathrm{mmol} / \mathrm{L}$, urine $\mathrm{NH}_{4}{ }^{+}<25 \mathrm{mmol} / \mathrm{L}$ ); (4) results of ammonium chloride loading tests in patients with a blood $\mathrm{pH}$ of $>7.35$. Ammonium chloride $(0.1 \mathrm{~g} / \mathrm{kg})$ was administered orally for three days. On the third day, the blood carbon dioxide combining power $\left(\mathrm{CO}_{2} \mathrm{CP}\right)$ and blood and urinary $\mathrm{pH}$ values were determined. A patient was defined as dRTA-positive if the blood $\mathrm{pH}$ and $\mathrm{CO}_{2} \mathrm{CP}$ decreased while the urine $\mathrm{pH}$ exceeded 5.5 (11-13) and was diagnosed with incomplete dRTA. dRTA patients with a blood $\mathrm{pH}$ of $<$ 3.5 were diagnosed with complete dRTA (5). Patients whose disease was considered to be a secondary form of dRTA, such as Sjögren's syndrome, obstructive uropathy, chronic active virus hepatitis or drug-induced nephropathy, were excluded (13). (6) Patients with a wide anion gap and high urine $\mathrm{pH}$ with a reduced eGFR were included when the $\Delta$ change in blood bicarbonate exceeded the $\Delta$ change in the blood anion gap.

The procedure for the urine titratable acid assay was as follows. Fresh urine was collected in the morning. The Urine $\mathrm{pH}, \mathrm{HCO}_{3}{ }_{3}$, titratable acid and $\mathrm{NH}_{4}{ }^{+}$values were tested within 30 minutes. The urine $\mathrm{pH}$ was measured at room temperature. A total of $5 \mathrm{~mL}$ of $\mathrm{HCl}$ of 0.1 molarity was added to $10 \mathrm{~mL}$ of urine, and the specimen was placed in boiling water for 15 minutes, after which it was cooled. The urine was titrated with 0.1 molarity $\mathrm{NaOH}$ to the original $\mathrm{pH}$, and the amount of $\mathrm{NaOH}$ was recorded in order to calculate the level of $\mathrm{HCO}_{3}$. The urine was then titrated with 0.1 molarity $\mathrm{NaOH}$ to a $\mathrm{pH}$ of 7.4 , and the amount of $\mathrm{NaOH}$ was recorded in order to calculate the level of titratable acid. A total of $10 \mathrm{~mL} 8 \%$ methanol at a $\mathrm{pH}$ of 7.4 was added to the specimen, and the solution was mixed. The mixture was subsequently titrated with 0.1 molarity $\mathrm{NaOH}$ to a $\mathrm{pH}$ of 7.4, and the amount of $\mathrm{NaOH}$ was recorded in order to calculate the level of $\mathrm{NH}_{4}^{+}$.

\section{Statistical analyses}

The SPSS version 11.5 software program was used for all the statistical analyses. The values are expressed as the mean \pm standard deviation $(\mathrm{X} \pm \mathrm{SD})$. The level of statistical significance was set at $\mathrm{p}<0.05$.

\section{Results}

Between March 1996 and July 2009, a total of 380 patients were diagnosed with dRTA. Most cases were secondary dRTA $(285 / 380,75 \%)$, and the most common underlying cause was Sjögren's syndrome $(118 / 285,41.4 \%)$. Other common causes included aristolochic acid nephropathy, medullary sponge kidney, drug-induced dRTA, HBV infection, etc. A total of 95 cases were primary dRTA $(95 / 380,25 \%)$, most of which were sporadic $(88 / 95,92.6 \%)$.

\section{Clinical manifestations}

A total of 95 patients were enrolled in the present study. The mean age was $38.79 \pm 20.32$ years $(2-82$ years). There were 40 men $(42.11 \%$, mean age $37.55 \pm 19.95$ years) and 55 women $(57.89 \%$, mean age $42.87 \pm 19.39$ years). There were no significant statistical differences between the mean ages $(\mathrm{p}=0.19)$. Among the 95 patients, 14 were children $(<18$ years), including two patients from consanguineous families, 
Table 1. Common Clinical Manifestation Analysis of 95 Cases

\begin{tabular}{llrr}
\hline & manifestation & number & Percentage (\%) \\
\hline common & muscle weakness & 65 & 84.2 \\
clinical & overdrinking due to thirsty & 22 & 23.16 \\
manifestation & and diuresis & & \\
& paralysis & 30 & 32.00 \\
& anorexia & 13 & 13.68 \\
& arthralgia & 10 & 10.53 \\
& dyspnea & 11 & 11.58 \\
& muscle ache & 10 & 11.00 \\
& acroanesthesia & 18 & 18.95 \\
& palpatation & 11 & 12.00 \\
& tic of limbs & 9 & 9.47 \\
& growth retardation in children & $9 / 14$ & 64.29 \\
renal & increased nocturia & 39 & 41.05 \\
involvement & urinary infection & 6 & 6.32 \\
manifestation & urinary lithiasis & 11 & 11.58 \\
& kidney calcification & 4 & 4.21 \\
& eGFR $<60 \mathrm{ml} /$ min/1.73m ${ }^{2}$ & 28 & 29.47 \\
\hline
\end{tabular}

Table 3. Analysis of Renal Tubular Function

\begin{tabular}{lrc}
\hline & No. & $\%$ \\
\hline complete RTA & $29 / 95$ & 30.5 \\
incomplete RTA & $66 / 95$ & 69.5 \\
Nephrogenic diabetes insipidus & $1 / 95$ & 1.05 \\
tubular proteinuria & $8 / 27$ & 29.6 \\
Increased urine $\beta_{2}$ microalbumin & $12 / 28$ & 42.9 \\
Increased NAG & $11 / 53$ & 20.7 \\
Increased RBP & $15 / 39$ & 38.5 \\
\hline
\end{tabular}

both of whom were 17-year-old boys (one patient exhibited neural hearing loss in the right ear). The mean systolic pressure and diastolic pressure values were $121.33 \pm 17.23$ and $77.25 \pm 11.96 \mathrm{mmHg}$, respectively.

The most common manifestations of dRTA included fatigue, increased nocturia, flaccidity and overdrinking due to thirst and diuresis. In this study, one patient had torsades de pointes. In addition to increased nocturia, the renal manifestations of dRTA included urinary lithiasis (Table 1).

\section{Analysis of the renal function}

The kidney function of the patients older than 16 years of age was evaluated using the Cock-Gault formula, whereas that of the patients younger than 16 years of age was evaluated using the Schwartz formula. The mean values of the glomerular filter rate according to the Cock-Gault and Schwartz formulas were $73.35 \pm 35.41 \mathrm{~mL} / \mathrm{min}$ and $77.12 \pm$ $41.28 \mathrm{~mL} / \mathrm{min}$, respectively. Among the patients, 37 (38.95\%), $33(34.74 \%), 19(20 \%)$, four $(4.21 \%)$ and two $(2.11 \%)$ had stage $1,2,3,4$ and $5 \mathrm{CKD}$, respectively.

\section{Analysis of the tubular function}

A total of 29 patients had complete distal RTA, while 66 had incomplete dRTA. The urine titratable tests revealed alkaline urine and abnormal urine acidification (Table 2). One patient exhibited dRTA complicated with nephrogenic diabetes insipidus with a low urine specific gravity and a volume
Table 2. Analysis of Urine Titratable Test

\begin{tabular}{lrrrr}
\hline & $\overline{\mathrm{X}} \pm \mathrm{SD}$ & $\begin{array}{r}\text { complete } \\
\text { dRTA }\end{array}$ & $\begin{array}{r}\text { incomplete } \\
\text { dRTA }\end{array}$ & p value \\
& & $\overline{\mathrm{X}} \pm \mathrm{SD}$ & $\overline{\mathrm{X}} \pm \mathrm{SD}$ & \\
\hline urine $\mathrm{pH}$ & $6.86 \pm 0.43$ & $6.93 \pm 0.67$ & $7.06 \pm 0.49$ & 0.37 \\
urine $\mathrm{TA}(\mathrm{mEg} / \mathrm{L})$ & $3.92 \pm 4.64$ & $3.40 \pm 3.93$ & $3.06 \pm 4.13$ & 0.74 \\
urine $\mathrm{NH}_{4}{ }^{+}(\mathrm{mEg} / \mathrm{L})$ & $17.85 \pm 9.23$ & $17.01 \pm 13.14$ & $17.57 \pm 10.07$ & 0.84 \\
urine $\mathrm{HCO}_{3}{ }^{-}(\mathrm{mEg} / \mathrm{L})$ & $9.01 \pm 4.67$ & $8.85 \pm 6.88$ & $12.09 \pm 7.08$ & 0.03 \\
\hline
\end{tabular}

Table 4. Blood and Urine Biochemical and Renal Function Analysis of 95 Cases

\begin{tabular}{lrr}
\hline & blood & urine \\
\hline $\mathrm{pH}$ & $7.36 \pm 0.06$ & $6.86 \pm 0.43$ \\
sodium & $140.75 \pm 3.50 \mathrm{mmol} / \mathrm{L}$ & $153.22 \pm 78.83 \mathrm{mmol} / 24 \mathrm{~h}$ \\
potassium & $3.23 \pm 0.64 \mathrm{mmol} / \mathrm{L}$ & $47.24 \pm 24.17 \mathrm{mmol} / 24 \mathrm{~h}$ \\
chloride & $107.59 \pm 5.84 \mathrm{mmol} / \mathrm{L}$ & $143.61 \pm 83.02 \mathrm{mmol} / 24 \mathrm{~h}$ \\
calcium & $2.18 \pm 0.18 \mathrm{mmol} / \mathrm{L}$ & $4.29 \pm 3.04 \mathrm{mmol} / 24 \mathrm{~h}$ \\
phosphate & $1.10 \pm 0.34 \mathrm{mmol} / \mathrm{L}$ & $15.48 \pm 8.95 \mathrm{mmol} / 24 \mathrm{~h}$ \\
urea nitrogen & $5.51 \pm 2.84 \mathrm{mmol} / \mathrm{L}$ & $219.83 \pm 93.21 \mathrm{mmol} / 24 \mathrm{~h}$ \\
creatinine & $88.86 \pm 61.41 \mathrm{umol} / \mathrm{L}$ & $8.00 \pm 3.19 \mathrm{mmol} / 24 \mathrm{~h}$ \\
uric acid & $268.52 \pm 90.09 \mathrm{umol} / \mathrm{L}$ & $2.76 \pm 1.05 \mathrm{mmol} / 24 \mathrm{~h}$ \\
\hline
\end{tabular}

of daily urine of 7,600 mL, which persisted after water deprivation and the vasopressin assay, as well as a normal sella turcica according to a computed tomography scan. Moreover, $8.33 \%(8 / 27)$ of the patients presented with tubular proteinuria (urine protein $<1 \mathrm{~g} /$ day) and low-molecularweight proteinuria on urine protein electrophoresis (Table 3).

\section{Laboratory data}

A total of 10 patients had leukocytopenia (6.2\%), while 33 had anemia (6.9\%). Most patients $(n=60,63 \%)$ had hypokalemia. The mean urine $\mathrm{pH}$ of the patients was $6.86 \pm$ 0.43 . The mean blood potassium, chloride, calcium and phosphate levels were $3.23 \pm 0.64,107.59 \pm 5.84,2.18 \pm 0.18$ and $1.10 \pm 0.34 \mathrm{mmol} / \mathrm{L}$, respectively. The mean urine potas-

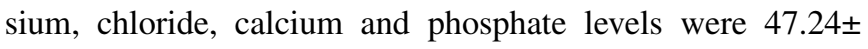
$24.17,143.61 \pm 83.02,4.29 \pm 3.04$ and $15.48 \pm 8.95 \mathrm{mmol} / \mathrm{L}$, respectively (Table 4 ). The mean urine calcium levels of the patients with and without urinary lithiasis were $0.10 \pm 0.04$ and $0.07 \pm 0.05 \mathrm{mmol} / 24 \mathrm{~h} / \mathrm{kg}$, respectively, and they demonstrated statistical significance $(\mathrm{p}=0.04)($ Table 5).

\section{Bone diseases}

Some patients were diagnosed with bone diseases, including osteoporosis (9/10), pathological bone fractures (6/95) and bone deformities (7/95), as well as retardation of bone age in children (3/14)(Table 6). The blood $\mathrm{pH}$, calcium and phosphate levels in addition to the urine calcium and urine phosphate levels were compared between the patients with and without bone diseases. The blood $\mathrm{pH}$ values of the patients with and without bone diseases were significantly different $(7.37 \pm 0.06$ and $7.32 \pm 0.06$ respectively, $\mathrm{p}=0.01$, Тable 5).

\section{Outcomes}

A total of 82 patients received treatment consisting of a 
Table 5. Comparison of the Patients with and without Renal Lithiasis and/or Kidney Calcification, and Patients with and without Bone Disease

\begin{tabular}{llrrrrrr}
\hline \multicolumn{2}{l}{ variables } & with $\mathrm{L}$ and C & without $\mathrm{L}$ and C & & $\mathrm{p}$ with BD & without BD \\
& $\mathrm{n}=11$ & $\mathrm{n}=84$ & $\mathrm{p}$ & $\mathrm{n}=22$ & $\mathrm{n}=73$ & $\mathrm{p}$ \\
\hline blood & $\mathrm{pH}$ & $7.36 \pm 0.06$ & $7.35 \pm 0.07$ & $\mathrm{NS}$ & $7.32 \pm 0.06$ & $7.37 \pm 0.06$ & 0.01 \\
blood & calcium & $2.18 \pm 0.13$ & $2.18 \pm 0.19$ & $\mathrm{NS}$ & $2.17 \pm 0.23$ & $2.12 \pm 0.26$ & $\mathrm{NS}$ \\
blood phosphate & $1.13 \pm 0.54$ & $1.09 \pm 0.28$ & $\mathrm{NS}$ & $2.06 \pm 8.12$ & $1.14 \pm 0.56$ & $\mathrm{NS}$ \\
urine $\mathrm{pH}$ & $6.97 \pm 0.58$ & $6.98 \pm 0.52$ & $\mathrm{NS}$ & & & & \\
urine calcium $(\mathrm{mmol} / 24 \mathrm{~h} / \mathrm{kg})$ & $0.10 \pm 0.04$ & $0.07 \pm 0.05$ & 0.04 & $0.08 \pm 0.05$ & $0.06 \pm 0.06$ & $\mathrm{NS}$ \\
urine phosphate & $13.87 \pm 6.69$ & $15.61 \pm 9.43$ & $\mathrm{NS}$ & $15.35 \pm 9.09$ & $14.60 \pm 8.10$ & $\mathrm{NS}$ \\
\hline
\end{tabular}

$\mathrm{L}$ and $\mathrm{C}$ : renal lithiasis and/or kidney calcification

BD: bone disease, including osteoporosis, bone deformity and growth retardation in children.

Table 6. Bone Disease of 95 Cases of dRTA

\begin{tabular}{lrr}
\hline presentations & number & Percentage (\%) \\
\hline osteoporosis & $9 / 10$ & 90 \\
bone pain & $7 / 95$ & 7.37 \\
bone fracture & $6 / 95$ & 6.32 \\
bone deformity & $7 / 95$ & 7.14 \\
retardation of bone age in children & $3 / 14$ & $21.43 \%$ \\
\hline
\end{tabular}

mixture of sodium and potassium citrate. Sodium bicarbonate, oral calcium and 25-hydroxyvitamin D3 were also prescribed according to the recovery status. The follow-up period ranged from two to seven years. One patient died of rectal cancer, while two received renal transplantation and the others had good prognoses.

\section{Discussion}

dRTA constitutes a group of disorders characterized by hyperchloremic metabolic acidosis with a normal anion gap. This condition is caused by distal tubular dysfunction in the excretion of protons and/or reabsorption of $\mathrm{HCO}_{3}$. Primary dRTA consists of sporadic and inherited types. Both autosomal-dominant and autosomal-recessive patterns have been reported in cases of primary dRTA. The presently reported genes associated with dRTA include SLC4A1, ATP6V1B1 and ATP6V0A4 (10). dRTA is caused by the defective acidification of the distal renal tubules, which makes it impossible to maintain a strong hydrogen concentration gradient between luminal and tubular cells and thus acidify urine under the circumstances of systemic acidosis, resulting in abnormally alkaline urine. The net urinary elimination of hydrogen depends on its buffering and excretion as TA (mainly $\mathrm{HPO}_{4}{ }^{2-}+\mathrm{H}^{+} \leftrightarrow \mathrm{H}_{2} \mathrm{PO}^{4}$ ), and $\mathrm{H}^{+}$is excreted as $\mathrm{NH}_{4} \mathrm{Cl}$ in the urine, simultaneously generating 'new' bicarbonate, which is added to the plasma $(2,14)$.

In this study, we found the most predominant manifestations to include muscle weakness, increased nocturia, paralysis and over drinking due to thirsty and diuresis. The most common laboratory abnormality was hypokalemia. Moreover, one patient had torsade de pointes. Dysfunction of contraction and dilution of the distal tubules can cause overdrinking due to thirst and increased nocturia. Moreover, previous authors have report that dRTA can be accompanied by nephrogenic diabetes insipidus $(15,16)$, which was diagnosed in one patient in our study.

Some patients have both distal and proximal tubular dysfunction. Low-molecular-weight (LWW) proteinuria, including that involving urine $\beta_{2}$ microalbumin, NAG ( $\mathrm{N}$-acetylbeta-D-glucosaminidase) and RBP (retinol binding protein), was detected. Although the mechanism underlying the proximal dysfunction observed in dRTA patients remains unclear, there are two possible explanations: endosomal dysfunction of proximal renal tubular cells and hypokalemic nephropathy (17-20). LMW proteins are filtered by glomeruli, reabsorbed via a receptor-mediated (i.e., megalin and cubilin) endocytic pathway and catabolized by proximal renal tubular cells. $\mathrm{H}^{+}$-ATPase participates in this process at the level of proximal renal tubular cells, which is why mutations of the subunits of $\mathrm{H}^{+}$-ATPase can induce proximal tubular dysfunction. Furthermore, there is evidence that the proximal tubular dysfunction noted in primary dRTA is reversible in association with relief of RTA following the administration of alkali therapy. Because our study is based on retrospective data, there is a lack of follow-up data in these patients.

In contrast with reports in the literature regarding the incidence of symptomatic nephrolithiasis (23\%) and nephrocalcinosis (77\%), hypokalemia (46.88\%) and bone disease (33\%) (21), we found a higher frequency of hypokalemia $(63.16 \%)$ and lower frequencies of nephrolithiasis (11.58\%), nephrocalcinosis $(4.21 \%)$ and bone disease $(23.16 \%)$. As for the low frequency of nephrolithiasis and nephrocalcinosis, we believe this finding is due to the low sensitivity of kidney ultrasound.

Chronic acidosis can cause growth retardation, osteoporosis, bone deformities and even bone fractures $(22,23)$. The present results revealed a significant difference in blood $\mathrm{pH}$ between the patients with and without bone disease. Unfortunately, we have no follow-up data regarding the relationship between improvements in bone disease and corrections in blood $\mathrm{pH}$.

The present study identified a significant difference in the urine calcium levels between the patients with and without nephrocalcinosis and/or nephrolithiasis $(2.18 \pm 0.20 \mathrm{mmol} / \mathrm{L}$ and $0.07 \pm 0.05 \mathrm{mmol} / 24 \mathrm{~h} / \mathrm{kg}$, respectively). This result is 
concordant with the findings of a previous study (7). In addition, there were no significant differences between the groups with respect to any other variables, including the blood and urine levels of phosphate and $\mathrm{pH}$. Hypercalciuria, which is always accompanied by hypocitraturia, is one of the most common manifestations of dRTA. However, the mechanism of hypercalciuria in dRTA patients remains unclear, although it may be due to increased calcium release from bone due to metabolic acidosis (24) or the downregulation of renal calcium transport proteins as a result of acidosis (25). Our laboratory examination method has some limitation in testing urine citrate; therefore, we have no data for the levels of urine citrate. Meanwhile, the differences in urine calcium between the patients with and without nephrocalcinosis emphasize the need to control the urine calcium and citrate levels. Several studies have demonstrated that an increased intake of potassium citrate decreases the risk of metabolic acidosis and citrate oxalate stones (26-28). In the present study, the patients received a mixture of sodium and potassium citrate administered orally. However, owing to the limited nature of this respective study, we were unable to determine the effects of the oral intake of citrate on nephrolithiasis.

The present results demonstrated that the most frequent clinical manifestations of dRTA include muscle weakness, increased nocturia, paralysis and growth retardation in children. We noted that approximately $40 \%$ of the patients exhibited proximal tubular dysfunction, primarily LWW proteinuria and reduced urine $\beta_{2}$ microalbumin, NAG and RBP levels. In addition, we found that hypercalciuria was correlated with the existence of nephrolithiasis and that correcting blood $\mathrm{pH}$ is important for the prevention and treatment of bone diseases caused by dRTA.

\section{The authors state that they have no Conflict of Interest (COI).}

\section{Acknowledgement}

This study was supported by grants from the National Basic Research Program of China 973 Program No. 2012CB517600 (No. 2012CB517604), National Natural Science Foundation of China (No. 81070560) and National Natural Science Foundation of China (No. 81070568).

Chunli Zhang and Hong Ren contributed equally to this work.

\section{References}

1. Schwartz GJ. Diagnosis of distal renal tubular acidosis: use of furosemide plus fludrocortisone versus ammonium chloride. Nat Clin Pract Nephrol 3: 590-591, 2007.

2. Pereira PC, Miranda DM, Oliveira EA, Silva AC. Molecular pathophysiology of renal tubular acidosis. Curr Genomics 10: 5159, 2009.

3. Rodriguez Soriano J. Renal tubular acidosis: the clinical entity. J Am Soc Nephrol 13: 2160-2170, 2002.

4. Ring $T$, Frische $S$, Nielsen S. Clinical review: Renal tubular acidosis: a physicochemical approach. Crit Care 9: 573-580, 2005.

5. Gregory MJ, Schwartz GJ. Diagnosis and treatment of renal tubu- lar disorders. Semin Nephrol 18: 317-329, 1998.

6. Stover EH, Borthwick KJ, Bavalia C, et al. Novel ATP6V1B1 and ATP6V0A4 mutations in autosomal recessive distal renal tubular acidosis with new evidence for hearing loss. J Med Genet 39: 796-803, 2002.

7. Bajpai A, Bagga A, Hari P, Bardia A, Mantan M. Long-term outcome in children with primary distal renal tubular acidosis. Indian Pediatr 42: 321-328, 2005.

8. Brown AS. Renal tubular acidosis. Dimens Crit Care Nurs 29: 112-119, 2010.

9. Nikali K, Vanegas JJ, Burley MW, et al. Extensive founder effect for distal renal tubular acidosis (dRTA) with sensorineural deafness in an isolated South American population. Am J Med Genet A 146A: 2709-2712, 2008.

10. Fry AC, Karet FE. Inherited renal acidoses. Physiology (Bethesda) 22: 202-211, 2007.

11. Bossini N, Savoldi S, Franceschini F, et al. Clinical and morphological features of kidney involvement in primary Sjögren's syndrome. Nephrol Dial Transplant 16: 2328-2336, 2001.

12. Oduwole AO, Giwa OS, Arogundade RA. Relationship between rickets and incomplete distal renal tubular acidosis in children. Ital J Pediatr 36: 54, 2010.

13. Ren H, Wang WM, Chen $X N$, et al. Renal involvement and followup of 130 patients with primary Sjögren's syndrome. J Rheumatol 35: 278-284, 2008.

14. Laing CM, Toye AM, Capasso G, Unwin RJ. Renal tubular acidosis: developments in our understanding of the molecular basis. Int J Biochem Cell Biol 37: 1151-1161, 2005.

15. Liu H, Tomoda F, Koike T, et al. A case of distal renal tubular acidosis complicated with renal diabetes insipidus, showing aggravation of symptoms with occurrence of diabetes mellitus. Nihon Jinzo Gakkai Shi (Japanese Journal of Nephrology) 53: 726-731, 2011 (in Japanese, Abstract in English).

16. Folami AO, Balfe JW, Robson WL, Halperin ML, Stinebaugh BJ. Coexistence of distal renal tubular acidosis and nephrogenic diabetes insipidus in two patients: implications for the pathogenesis of distal renal tubular acidosis. Clin Invest Med 1: 105-109, 1978.

17. Watanabe T. Proximal renal tubular dysfunction in primary distal renal tubular acidosis. Pediatr Nephrol 20: 86-88, 2005.

18. Yamamoto K, Cox JP, Friedrich T, et al. Characterization of renal chloride channel (CLCN5) mutations in Dent's disease. J Am Soc Nephrol 11: 1460-1468, 2000.

19. Norden AG, Lapsley M, Igarashi T, et al. Urinary megalin deficiency implicates abnormal tubular endocytic function in Fanconi syndrome. J Am Soc Nephrol 13: 125-133, 2002.

20. Igarashi $T$, Kawato $H$, Kamoshita S. Reversible low-molecularweight proteinuria in patients with distal renal tubular acidosis. Pediatr Nephrol 4: 593-596, 1990.

21. Caruana RJ, Buckalew VM Jr. The syndrome of distal (type 1) renal tubular acidosis. Clinical and laboratory findings in 58 cases. Medicine (Baltimore) 67: 84-99, 1988.

22. Sharma AP, Singh RN, Sharma RK, Kapoor R, Filler G. Bicarbonate therapy improves growth in children with incomplete distal renal tubular acidosis. Pediatr Nephrol 24: 1509-1516, 2009.

23. Domrongkitchaiporn S, Pongsakul C, Stitchantrakul W, et al. Bone mineral density and histology in distal renal tubular acidosis. Kidney Int 59: 1086-1093, 2001.

24. Rocher LL, Tannen RL. The clinical spectrum of renal tubular acidosis. Annu Rev Med 37: 319-331, 1986.

25. Nijenhuis T, Renkema KY, Hoenderop JG, Bindels RJ. Acid-base status determines the renal expression of $\mathrm{Ca}^{2+}$ and $\mathrm{Mg}^{2+}$ transport proteins. J Am Soc Nephrol 17: 617-626, 2006.

26. Tapaneya-Olarn W, Khositseth S, Tapaneya-Olarn C, et al. The optimal dose of potassium citrate in the treatment of children with distal renal tubular acidosis. J Med Assoc Thai 85(Suppl 4): S1143-S1149, 2002. 
Intern Med 54: 725-730, 2015 DOI: 10.2169/internalmedicine.54.9421

27. Domrongkitchaiporn S, Khositseth S, Stitchantrakul W, Tapaneya-olarn W, Radinahamed P. Dosage of potassium citrate in the correction of urinary abnormalities in pediatric distal renal tubular acidosis patients. Am J Kidney Dis 39: 383-391, 2002.
28. Preminger GM, Sakhaee K, Skurla C, Pak CY. Prevention of recurrent calcium stone formation with potassium citrate therapy in patients with distal renal tubular acidosis. J Urol 134: 20-23, 1985.

(C) 2015 The Japanese Society of Internal Medicine http://www.naika.or.jp/imonline/index.html 